\title{
“¿Hacemos turismo o viajamos, Biscuter?” Manuel Váz- quez Montalbán y las modalidades del viaje
}

\section{IVANNE GALANT}

Este artículo nace del descubrimiento de una edición del Viaje a España de Théophile Gautier prologada por Manuel Vázquez Montalbán, publicada en 1985 por la editorial Taifa. A raíz de esto, se constituyó un corpus montalbaniano relacionado con el viaje, sabiendo que era un motivo recurrente de la obra literaria de Montalbán ${ }^{1}$. El prólogo al libro de Gautier, bastante crítico hacia el romántico francés, sirvió para iniciar una reflexión sobre la aportación del escritor barcelonés a la problemática de los especialistas del viaje, a través de sus personajes o a través de textos de varios tipos. La obra que más se utilizó fue Milenio, de donde proviene la cita-título de este artículo. Los dos volúmenes de Milenio proporcionan un gran abanico de citas que servirán aquí para ilustrar el estado de la cuestión teórica sobre la oposición conceptual y semántica que existe, que se construye o que se inventa entre viaje y turismo ${ }^{2}$. Tras estas consideraciones teórico-literarias, se analizará el punto de vista que Montalbán expresa en Crónica sentimental de España, con un apartado titulado "Turismo y libertad”, en el prólogo al Viaje de Gautier, así como en una guía de viaje de Barcelona que se publicó en Francia en 1987. Terminaremos mostrando que, hoy en día, en una Barcelona hiperturistizada, la existencia de un turismo literario basado en la vida y la obra de Montalbán puede constituir un puente entre el viaje, el turismo y la literatura.

\section{Teoría del viaje y del turismo, ilustrada por Carvalho y Biscuter}

A menudo se oponen viaje y turismo, pero pocas veces la oposición aparece satisfactoria. Existen varias definiciones, varias explicaciones que van desde la etimología hasta la sociología, y que muchas veces se basan en unas ideas preconcebidas. Según las épocas, los teóricos del viaje intentaron destacar varias diferencias entre los dos términos.

1 Véase "La vuelta al mundo de Pepe Carvalho", que es el Epílogo conmemorativo del $25^{\circ}$ aniversario de Carvalho y aparece en la edición de Planeta de Los pájaros de Bangkok, en 1997 y que detalla todos los viajes de Carvalho.

2 Edición consultada para este trabajo: Manuel Vázquez Montalbán, Milenio Carvalho, Barcelona: Planeta, Booket, 2010. 
En Milenio, último periplo de Carvalho y Biscuter, los personajes reflexionan a menudo sobre la oposición entre el turismo y el viaje. En un artículo titulado "Viaje al fin del mundo: Política del tiempo y el espacio en Milenio Carvalho", Mari Paz Balibrea comenta que "la cuestión aquí es que Carvalho se deja interpelar por la lógica del turismo global y piensa en sus opciones de viaje como mediadas por un mercado tan sofisticado que es capaz de acomodar cualquier fantasía. Su esquema para pensar el viaje corresponde al paradigma posmoderno" (Balibrea 201). Los protagonistas se quieren considerar como "viajeros infinitos" (Vázquez Montalbán, Milenio Carvalho 532) al mismo tiempo que contemplan los estragos del turismo en una sociedad globalizada.

$\mathrm{Si}$ nos fijamos en las ocurrencias de las palabras relacionadas con el viaje y el turismo en los dos volúmenes de Milenio, vemos que las derivadas del "viaje" son mucho más numerosas que las derivadas del turismo (Milenio 1: viaj- 248/ turis- 77 veces/ Milenio 2: viaj- 232/ turis- 65 veces) Podríamos decir que el autor como sus personajes sienten más apego al viaje, siendo una forma mejor considerada - y volveremos sobre esta idea después. Esto se debe al doble sentido de la palabra "viaje", desplazamiento y estancia, así como a la existencia del verbo "viajar".

En cuanto a la etimología, base de la diferencia entre ambos términos, Madame Lissieux precisa en Milenio que "tour" implica regreso:

He tardado años en reaccionar y me ha ayudado mucho haber accedido a la condición de viajera, de viajera, insisto, no de turista. Paul Bowles decía que la diferencia entre un viajero y un turista consiste en que éste sabe cuándo comienza y termina su viaje; un viajero de verdad, no: sabe cuándo comienza, pero no cuándo termina. — ¡Como nuestro viaje, jefe! ¡Somos viajeros! (Vázquez Montalbán, 37) 3

\section{El viajero-explorador $v s$ turista-idiota del viaje}

El desprecio hacia el turista es algo que se observa tanto en la obra de Montalbán como en el discurso común. Cabe recordar que la palabra "turista" no siempre tuvo un sentido peyorativo: en 1838, Stendhal, por anglofilia y por esnobismo, se enorgullecía de ser un turista, cuando publicó Memorias de un turista. Asimismo, Gérard de Nerval aceptó esta

\footnotetext{
3 Otra diferencia que existe es la espacial: para muchos, viajar significa ir lejos. Pero no parece satisfactoria esta diferencia en nuestro mundo porque con el progreso técnico, las distancias se acortan y además se puede ir muy lejos para "hacer turismo", lo que se ve en el periplo de Carvalho y Biscuter.
} 
condición en Voyage en Orient (1843), hablando de "peregrinaciones de un turista". Sin embargo, la imagen del viajero por placer empieza a degradarse bajo la pluma humorística del suizo Rodolphe Töpffer, en sus Voyages en zig-zag, (1844 y 1853). En 1850, Gustave Flaubert sentía vergüenza por ser turista: escribió a Louis Bouilhet en vísperas de una excursión: "Esto solo será un viaje de turista, joh! no nos queda ni tiempo ni dinero"4. Así, ya promediado el siglo XIX, burlarse de los turistas era algo común: Sylvain Venayre evoca el caso del teatro donde aparecen personajes de turistas que iban garabateando de manera frenética en pequeñas libretas 5 . Como lo señala el equipo "Mobilités Itinéraires, Territoires", el desarrollo del turismo y su estigmatización empezaron casi al mismo tiempo (MIT 11). Hasta en el diccionario francés Le Littré se notaba en 1873 un matiz peyorativo que añadía en su definición palabras como "desocupación" y "especie de" que muestran que esta práctica no se comprende muy bien:

Se dice de los viajeros que solo recorren países extranjeros por curiosidad o desocupación, que hacen una especie de gira por países que suelen visitar sus compatriotas. Designa sobre todo a los ingleses que viajan por Francia, Suiza e Italia (Littré) 6 .

El mismo equipo de investigación precisa que la caricatura se amplificó con la democratización del viaje, lo que se nota en Milenio donde se pueden encontrar retratos caricaturescos de turistas, como cuando se habla del "turismo interior de fin de semana: con la tortilla de patatas en la fiambrera o la posibilidad de asar cordero, de reproducir el ritual de la costellada, tan religioso como cualquier otro ritual religioso." (Vázquez Montalbán 134)

La visión caricaturesca creciente corresponde a la asociación de la práctica del turismo con el ocio y del tiempo de su advenimiento con la -

4 "Ce ne sera guère qu'un voyage de touriste (oh!): il ne nous reste ni temps ni argent" Flaubert, Correspondance à Louis Bouilhet, 1850, citado por JeanDidier Urbain, "Touriste", in Laurent Gervereau (éd.), Dictionnaire mondial des images, Paris, Nouveau Monde, 2010, 1590-1593, aquí 1590-1591.

5 Ponencia de Sylvain Venayre pronunciada durante las jornadas dedicadas al proyecto transversal del ILCEA4 "Passages, Ancrage", Université Stendhal, Grenoble 3, 16 octobre 2015 y titulada "Le récit de voyage est-il un genre littéraire? Naissance d'un débat (1780-1880)".

6 "Se dit des voyageurs qui ne parcourent des pays étrangers que par curiosité et désœuvrement, qui font une espèce de tournée dans des pays habituellement visités par leurs compatriotes. Se dit surtout des voyageurs anglais en France, en Suisse et en Italie". 
aparición de las vacaciones pagadas, la urbanización, la moda de las residencias secundarias, la publicidad y el progreso técnico.

El turismo sería entonces unas vacaciones, una manera de ocupar un tiempo libre, cuando el viaje se definiría como más iniciático, lo que opone de manera caricaturesca el placer y la cultura, una pena cuando se sabe que los ingleses del Grand Tour habían asimilado completamente el "prodesse" y "delectare", se divertían y aprendían cosas a la vez. El viajero sería más bien un explorador, libre, abierto a lo desconocido, propenso a visitar sitios inexplorados, dándole tanta importancia al trayecto como al destino, cuando el turista se suele identificar con el "idiota que viaja", para retomar una expresión de Jean-Didier Urbain ${ }^{7}$, es decir un viajero bajo tutela con comportamientos de borregos, más consumidor que explorador

En Milenio, se asocian comportamientos dignos del idiota del viaje, del turista, como por ejemplo la compra de recuerdos:

Por el camino de descenso compraron camisas pescadoras, sutiles blusas blancas bordadas, camisetas turistizadas, un vestuario que sólo podía exhibirse en Grecia y en verano, con el que Carvalho trató de provocar el retorno de Biscuter, todavía viajero tras la estela fugitiva de madame Lissieux (Vázquez Montalbán 53-54).

El tema del recuerdo para el turista aparece aquí en forma de burla y caricatura, pero se trata de una práctica que ya existía en el siglo XIX. El recuerdo de viaje es algo que evoluciona al mismo tiempo que la práctica del viaje: la democratización del viaje implica la producción en masa de souvenirs, según la ley de la oferta y la demanda. El souvenir se inserta en el mecanismo del estereotipo: representa a menudo los objetos de la tradición los cuales no evolucionan, inscribiéndose así en una intemporalidad inherente al cliché, como si la figurita o el objeto comprado fuese una encarnación del cliché.

\section{Balance / Problemas de léxico}

Si el viajero es él que descubre y el turista él que sigue los pasos del primero, sería lógico pensar que a medida que se conoce el mundo, se

7 Véase Jean-Didier Urbain, L'idiot du voyage: histoires de touristes, Paris, Payot, 1991 (traducción española: El idiota que viaja: relatos de turistas, Madrid, Endymion, 1993). 
viaja cada vez menos. Así, el hecho de pasar de un término a otro se relaciona con la evolución del mundo, entonces ¿para qué darle un sentido peyorativo a la palabra "turista" hasta el punto en que se convirtiera en un insulto? La jerarquía entre los dos viene de una cuestión de percepción, percepción de su propia estancia y mirada de la sociedad sobre ella. Todo es cuestión de punto de vista, como lo dice Bertrand Lévy:

La identidad está forjada tanto por el sentimiento subjetivo de pertenencia como por el espejo tendido desde lo exterior. La identidad del viajero y la del turista no escapan de esta regla. Existe un sentimiento vivido que no deberíamos descuidar: según las circunstancias, nos sentimos más o menos en la piel de un viajero o de un turista, y visto desde fuera, puede existir una contradicción entre la percepción vivida por el sujeto y la percepción de la alteridad. Así, nos consideramos a menudo como viajero, pero para los demás (turistas o autóctonos), no somos más que un turista entre otros. Las definiciones deben tomar en cuenta estos dos puntos de vista, interno y externo (Lévy 134) ${ }^{8}$.

Estas representaciones se basan en estereotipos: por una parte, el viajero tiene "cualidades esenciales de la condición humana: el sentido del movimiento, el sentimiento de libertad, la audacia, e incluso el heroísmo", y por otra parte el turista corresponde a "comportamientos gregarios, actividades de ocio fáciles, un placer superficial" (Lévy 134)9. Ante esas representaciones caricaturescas, Dean McCannell, autor de un libro sobre la figura del turista afirma que el debate no es fecundo y que estas consideraciones no hacen nada más que erigir a unos hombres contra otros hombres que, de hecho, a veces son los mismos (Mc Cannell 589603). Igualmente, otra especialista intenta neutralizar la competencia entre los dos: Céline Gaudier habla de la figura de un "tercer hombre"

$-$

8 "L'identité est forgée autant par le sentiment subjectif d'appartenance que par le miroir tendu de l'extérieur. L'identité du voyageur et du touriste n'échappe pas à cette règle. Il existe un sentiment vécu que l'on aurait tort de négliger (MIT, 2002): d'après les circonstances, on se "sent" plus ou moins dans la peau d'un voyageur ou d'un touriste, et vu de l'extérieur, il peut y avoir contradiction entre la perception vécue par le sujet et la perception de l'altérité: ainsi, on se considère souvent voyageur, mais pour les autres (touristes ou autochtones), on n'est qu'un touriste parmi d'autres. Les définitions doivent tenir compte de ces deux points de vue, interne et externe.

9 "des qualités idéales de la condition humaine: le sens du mouvement, le sentiment de liberté, l'audace, voire l'héroïsme"; des comportements grégaires", des loisirs faciles, un "plaisir superficiel". 
que puede tener actitudes o comportamientos de viajero y de turista durante un mismo viaje (Gaudier 125). Esto se ve en Milenio cuando Carvalho quiere huir de los caminos turísticos pero actúa como los turistas, afirmando que una visita relámpago a un museo será suficiente (queriendo quizás verlo, para poder contarlo después):

Esto va en serio, Biscuter. Mañana hay que subir temprano al Partenón para ver las piedras y no los culos de millares de turistas con celulitis reptando hacia las glorias arqueológicas del templo de Atenea y las Cariátides. También quisiera estar cinco minutos en el museo de Atenas. Tiempo suficiente para ver un glorioso Poseidón de bronce que se mueve como si estuviera vivo, como si estuviera recién pescado, y un niño subido a un caballo y expresando el movimiento como sólo podía expresarse en la época helenística (Vázquez Montalbán 53).

Los idiomas, ante la difícil resolución de la diferencia entre viaje y turismo y la connotación peyorativa de la palabra "turismo" forman expresiones a partir de cada una de las palabras. Hablan a veces de "turismo cultural" - expresión empleada en Milenio -, un turismo que permite cambiar de horizonte, ensancharlo y al revés, hablamos de "viaje turístico" o de "viaje de placer" para utilizar la expresión de Carvalho y Biscuter.

\section{Manuel Vázquez Montalbán y el viaje a España}

\section{Unas reflexiones generales sobre el turismo.}

En un artículo de Antonio Martínez Puche, se hace referencia a una frase que hubiera escrito Manuel Vázquez Montalbán en el prólogo de una guía de turismo. Aunque la fuente original fue imposible de localizar a causa de las discrepancias que existen en las bibliografías -Martínez Puche cita a otro universitario, Dolores Vidal, pero cuando remonta el hilo de los orígenes de la cita, no aparece referenciada de manera correcta y completa en los catálogos bibliográficos-, se supone que Vázquez Montalbán escribió lo siguiente:

los movimientos migratorios turísticos se han convertido en una industria floreciente y, hasta incluso, en la industria hegemónica de algunos países. ¿Se conocen mejor los pueblos gracias al turismo? No. Los viajeros masificados viajan en compañía de prejuicios y tópicos de toda clase y son pocos aquellos que salen de los circuitos turísticos prefigurados para entrar en con- 
tacto con los hombres, las mujeres, las cosas, los saberes del país que visitan (Martínez Puche, 157).

Además de esta referencia, habla de la dificultad de ser un viajero lucido en un mundo dominado por la industria y el mercado en un artículo titulado "Turismo, Medio de incomunicación de masas", publicado en marzo del 1970 en la revista Construcción, Arquitectura, Urbanismo $(C A U)$ :

Se sigue cultivando una imagen romántica del turista como viajero lúcido que visita otro país, observa libremente sus costumbres y sus normas de convivencia y extrae unas consecuencias. Esta imagen del turista perfecto corresponde al siglo XIX cuando escritores como Musset o Stendhal hacían turismo cualitativo y después literatura. Este turista cualitativo existe en la actualidad; Pero es minoritario, poco determinante (Vázquez Montalbán 11).

Critica también la lacra del turismo que representa "un compromiso de hipoteca total" para los países que le consagran mucha parte de su actividad, presupuesto o mano de obra. En este artículo se observa un punto de vista muy crítico sobre la práctica del turismo en general. La violencia de las palabras, el compromiso por este tema, son pruebas del interés de Montalbán por este ocio que empezaba a globalizarse en aquella época y que, por supuesto, afectaba España.

"Turismo y libertad", Crónica sentimental de España, 1971

En Crónica sentimental de España, que inicialmente se publicó en forma de artículos en la revista Triunfo en 1969, encontramos un apartado titulado "Turismo y libertad". Vázquez Montalbán pinta una España turistizada, compartiendo su sentimiento acerca de las ideas preconcebidas que circulan sobre el turismo: pone en duda el hecho de que sea realmente el turismo una práctica que enriquezca a la población, habla del tópico del bikini, relacionando "la liberalización de las costumbres y la nueva sociedad del ocio a una progresiva despolitización de la ciudadanía" (Fuentes Vega 65). Además de esto, se evoca el tema de la imagen folclórica para satisfacer a la "extranjería":

La extranjería ha penetrado en nuestros huesos como ese primer frío de otoño que sorprende la inercia de la ventana abierta. Cuando el Cordobés, el torero de los años sesenta, despliega el capote, lo hace, básicamente, para la extranjería. Ellos piden y nosotros damos. Y la extranjería europea sólo nos deja la falsa impresión de una equivalencia falsa. A ellos les interesa esta España turística, con paella y cordero al chilindrón, con sol y paisaje destro- 
“Hacemos turismo o viajamos, Biscuter?” Manuel Vázquez...

zado por los rascacielos del verano. Y para excitarse quieren toreros que se arrimen, poetas que se arrimen, obreros que se arrimen..., pero estos últimos que se arrimen en invierno; el verano que se lo dejen limpio y en paz (Vázquez Montalbán, “Turismo y Libertad” 120).

Así, según Montalbán, siendo el turismo una manera de granjear y acumular divisas, los españoles han aceptado ser lo que la "extranjería" esperaba de ellos por dos motivos: la promoción por el franquismo de una "España diferente" capaz de acoger un turismo de masas basado en el sol y la playa así como una imagen romántica no superada y aun glorificada por el régimen en vigor (el torero). Acerca de la responsabilidad de los románticos en la representación errónea del pueblo español, cabe estudiar de manera detenida el prólogo al Viaje por España de Théophile Gautier.

\section{Vázquez Montalbán versus Gautier}

La edición del Viaje a España de Théophile Gautier, publicada en 1985 por la editorial Taifa, consta de cinco páginas cuya estructura presentaremos a continuación. Tras citar el poema "Carmen" de Gautier, presenta al Gautier poeta, a caballo entre el romanticismo y Baudelaire. Después, relaciona la obra de Gautier con España: "han superado la obsolescencia como peligro literario número uno y pertenecen al eterno revival de lo que siempre no envejece". Desarrolla la relación entre Gautier y el tema español, subrayando la distancia existente entre sus ideas y su literatura, lo que califica de "pose literaria". Así, para Montalbán, existen dos facetas del escritor francés: el Gautier imaginativo y el Gautier fabulador. En esto, es al propio Montalbán a quien se podría calificar de fabulador cuando menciona la figura del especialista greco-turco Menelao Sostrakis misteriosamente desaparecido que hubiera evocado, a su vez, la existencia de dos Gautier: "un pulcro Gautier de camafeo detallista" y un Gautier "dispuesto a enriquecer el conocimiento mítico de la Europa mitológica". Este especialista es un personaje inventado, no tenemos la menor duda de esto cuando Montalbán se refiere con mucha ironía a un artículo suyo, supuestamente publicado en La revue des Recherches inutiles. Con estas informaciones, Vázquez Montalbán alude al hecho según el cual, para Gautier, España estaba a la periferia de Europa y en sus libros, Gautier no logró superar la descripción de lo que ya se conocía, es decir la Espana de los clichés. El último párrafo es particularmente interesante:

Desde culturas fuertes, como sus monedas, Gautier en el siglo XIX y Dos Passos y Hemingway en el siglo XX, vieron tan imparcialmente España que ni pudieron ni necesitaron pasar de "lo aparencial". Sin embargo, el encanto 
y el mérito de Gautier es que su escritura y relectura hacía objetivamente inútiles todas las españolas posteriores (Vázquez Montalbán 12).

Poniendo en duda el crédito de Gautier, insiste en la dificultad para los españoles de desprenderse de la visión que de los mismos difundió el escritor romántico francés, una visión basada en los clichés y tópicos que se encontraron en la literatura posterior (el costumbrismo, por ejemplo) y que impregnaron también los escritos de los viajeros extranjeros. Siendo Vázquez Montalbán de Barcelona, y sintiendo apego por su ciudad, cabe observar de más cerca lo que escribió Gautier sobre Barcelona.

Le dedicó pocas líneas a la capital catalana: es la última página del viaje por España. En ésta, Gautier dice que sus compañeros de viaje y él tenían ganas de volver a la "vida civilizada" que habían olvidado durante seis meses - ¿de allí quizás parte del resentimiento del prologuista? Explica que, tras haber cogido un barco en Gibraltar, se quedaron solamente unas horas en Barcelona. Obsesionado quizás por la idea del retorno a Francia, compara la ciudad condal con Marsella:

El aspecto de Barcelona es parecido al de Marsella, y el tipo español apenas se ve; los edificios son grandes, regulares, y sin los amplios pantalones de pana azul y las grandes barretinas rojas de los catalanes, podría uno creerse en una ciudad de Francia. A pesar de su Rambla, bordeada de árboles, de sus hermosas calles trazadas a cordel, Barcelona tiene un aire un poco afectado y tieso, como todas las ciudades rodeadas muy estrechamente de fortificaciones. La Catedral es muy hermosa, sobre todo en el interior, que es sombrío, misterioso, casi atemorizante. Los órganos son de factura gótica y se cierran con grandes tableros cubiertos de pinturas; una cabeza de sarraceno hace unos horribles gestos bajo el colgante que lo sostiene. Bellas arañas de siglo $\mathrm{XV}$, caladas como relicarios. (...) La calle de la Platería deslumbra los ojos por sus escaparates, relucientes de alhajas, y, sobre todo, de enormes pendientes, del tamaño de racimos de uva, de una riqueza pesada y maciza, un poco bárbara, pero muy majestuosa, y que compran principalmente las labriegas acomodadas (Gautier 330).

Frente a las ideas preconcebidas que difundieron los relatos de viaje de los franceses, así como las guías de viaje, hubo dos tipos de reacciones en España: unas voces empezaron a levantarse ya en la segunda mitad del siglo XIX para restablecer la verdad con un discurso más en adecuación con la realidad que con la ilusión mientras que otros consideraron que había que corresponder con esta idea de España, para agradar a los viajeros. Los autores de guías de viaje sobre España tuvie- 
ron mucha responsabilidad en la imagen que se tenía del país, y en una ocasión, Vázquez Montalbán actuó como tal.

\section{Vázquez Montalbán autor de guía}

A pesar de las críticas frecuentes hacia el turismo, Manuel Vázquez Montalbán, en el año 1987, o sea tres años antes del libro sobre Barcelona, publicó un texto para una guía de viaje. Sin embargo, no se trata de una publicación acorde con los estándares del género, se trata de una "guía íntima" por la editorial francesa Autrement. Esta colección de guías invita a sus lectores a cambiar la manera de viajar: "una guía de los barrios, de los sitios, de la gente. Como si se conociera a alguien in situ, iniciado a los ritos y ritmos de la ciudad, que nos propone un doble viaje en lo hermoso, en lo humano"10.

La guía de Barcelona de 1987 contiene un texto de Vázquez Montalbán titulado "Résurgences des villes enfouies". El autor presenta Barcelona como una ciudad compuesta de varias ciudades ocultas, escondidas, con diferentes arqueologías, diferentes historias. Admite que en Barcelona uno se puede comportar como un turista o como un "rastreador de arte" ("pisteur d'art"). Acerca de la Barcelona turística, éstas son sus palabras:

Barcelona puede ofrecer, en el sector del turismo, tanto como cualquiera otra ciudad, con, además, esas diferentes visiones de lo que tuvo y que conserva, de lo que le destruyeron y volvieron a construir, su nuevo tejido urbano de la democracia, una democracia que es un tejido urbano. Puede ofrecer hoteles, arte, museos, putas, camareros y concertistas, noches inolvidables y noches olvidables, excursiones en la Costa Brava (a cien kilómetros) o en los Pirineos (a ciento cincuenta), el mar y la montana, un excelente clima, una contaminación tolerable sobre todo cuando el viento sopla y limpia esta ciudad situada entre mar y colinas. ${ }^{11}$

10 "Un guide des quartiers, des lieux, des gens. Comme si l'on connaissait quelqu'un sur place, initié aux rites et rythmes de la ville, qui nous propose un double voyage dans le beau, dans l'humain".

11 "Barcelone peut offrir, sur le plan du tourisme, autant que n'importe quelle autre ville, avec, en plus, ces différentes visions de ce qu'elle a eu et qu'elle garde, de ce qu'on lui a détruit et reconstruit; son nouveau tissu urbain de la démocratie, une démocratie faite tissu urbain. Elle peut offrir des hôtels, de l'art, des musées, des putains, des garçons de café et des concertistes, des nuits inoubliables et des nuits oubliables, des excursions sur la Costa Brava (à cent kilomètres) ou dans les Pyrénées (à cent cinquante), la mer et la montagne, un 
Lo que resalta de este ensayo es la posibilidad de tener varias lecturas de Barcelona. El proyecto es de saludar, ya que no ofrece al lector un itinerario delimitado: son más bien unas reflexiones personales que no ayudaran a visitar de manera superficial la ciudad sino a comprenderla, en todos los sentidos de la palabra. Sin embargo, no se puede pasar por alto dos cosas. Primero, esta colección de guías se dirige a cierto tipo de viajero. La concepción elitista del viaje se percibe en un apartado llamado "Barcelone dans un Keepall", siendo el Keepall un bolso de viaje de la marca Louis Vuitton, presentado en la guía como el equipaje ideal para los pequeños viajes. No corresponde entonces con el tipo de equipaje utilizado por las clases medias, no se trata aquí de turismo popular. Segundo, este mismo apartado se aproxima a la guía tradicional ya que da la lista de todo lo que hay que ver en Barcelona: ¿acaso anula esto la tentativa de un viaje más libre que proponía el texto de Montalbán? Esto dependerá de la recepción y de la lectura personal de cada lectorviajero...

\section{Conclusiones}

Hemos visto entonces hasta qué punto Montalbán estaba interesado en la temática del viaje, no solo en el mundo de la ficción, dadas las reflexiones que hacen eco con las problemáticas de su época cuando se habla de un mundo globalizado sino también en textos más personales y comprometidos con esta temática. La oposición viaje-turismo es difícil de resolver, pero notamos en la obra de Montalbán intentos de luchar contra los estragos del turismo y los clichés creados y fomentados por los diferentes discursos viáticos. Carvalho y Biscuter nos enseñaron que en un mundo turistizado, todos tenemos comportamientos dignos de borregos. Pero Montalbán insistió en la posibilidad de otro viaje, más allá del turismo superficial basado en los clichés. Además, en Milenio, como lo mostró Georges Tyras en un artículo titulado "Milenio Carvalho, una vuelta al mundo de la literatura", "planea la tentación utópica de un viaje sin retorno", se busca el sitio del que no se quiere regresar. Este lugar podría ser la cárcel porque "el viaje demuestra a la vez que el movimiento se demuestra huyendo y que no hay huida posible" (Tyras 548). Así, Milenio también pone de relieve la vacuidad del viaje.

excellent climat, une pollution tolérable surtout lorsque le vent souffle et nettoie cette ville située entre mer et collines". 
Ahora bien, en la Barcelona hiperturistizada que conocemos hoy en día, Carvalho y Montalbán se han convertido en patrimonio cultural. En Barcelona, se crearon dos rutas, dedicadas al detective y a su creador. Destacamos una iniciativa pública, gratis, cuyo itinerario se encuentra en la página web de turismo de Cataluña ${ }^{12}$ así como una privada, de pago. El primer itinerario se centra en el autor. Empieza por Vallvidrera, "balcón sobre la ciudad", "mirador excepcional" donde se mudó en 1978 y donde Pepe Carvalho vivía:

La ruta puede comenzar tomando el funicular que lleva hasta la plaza de Pep Ventura, en el centro de Vallvidrera. Desde la estación se puede acceder a un mirador que ofrece excelentes vistas sobre la gran ciudad que acabamos de dejar atrás. Así describe Carvalho la gran urbe vista desde Vallvidrera: "Amanecía por entre las ramas de los árboles, Barcelona como una maqueta de sí misma, a los pies de la sierra de Collserola, le confirmaba dónde estaba y quién era". (...) Desde la plaza de Vallvidrera se puede tomar la calle del Alcalde Miralles, que lleva hasta el mercado, y desde allí la calle dels Reis Catòlics, por la que se llega hasta el Centro Cívico, situado en el número 1634.(...) Siguiendo por la misma calle se encuentra, a poco más de medio kilómetro, el pantano de Vallvidrera, una pequeña maravilla de la ingeniería construida por Elies Rogent en el siglo XIX, cuyo objetivo era recoger el agua de las rieras de la zona y canalizarla hasta el barrio de Sarrià a través del túnel Mina Grott. De regreso a la estación del funicular se pasa por la parroquia de Santa Maria, de estilo gótico tardío. Antes de tomar el funicular de regreso a la ciudad es recomendable otra visita al mirador que se encuentra encima de la estación para recordar las palabras de Carvalho: "Una de las ventajas de vivir en Vallvidrera es que te puedes despedir de toda una ciudad con una sola mirada".

El segundo itinerario lo organizó en el 2013 la agencia de viajes especializada en rutas enoturísticas Viemocions, con ocasión del décimo aniversario de la muerte del escritor. Con un precio de 85 euros, un guía acompaña grupos de no más de 12 personas y juntos visitan la coctelería Boadas para tomar un coctel de cava, el restaurante Can Lluís para probar buñuelos de bacalao y el restaurante Casa Leopoldo, donde se organiza una cena. Se incluye una visita al barrio del Raval, con explicaciones sobre la vida del escritor, así como una lectura de varios fragmentos de sus obras (los participantes recibieron un libro con dichos extractos).

${ }^{12} \mathrm{http}: / /$ www.catalunya.com/itinerario-manuel-vazquez-montalban-delfunicular-de-vallvidrera-a-la-ermita-de-santa-maria-24-1-81 ?language $=\mathrm{fr}$, obtenida el 17/09/2018. 
Además de estas dos iniciativas, cabe decir que las guías de viaje también evocan al dúo literario entre sus páginas, haciendo de él un elemento más del patrimonio barcelonés. Sin embargo, aún no proponen ruta o itinerario: el formato que más se encuentra es un apartado sobre el escritor en las partes dedicadas a las celebridades de la ciudad o a los protagonistas literarios. La guía Cartoville es la única que hace coincidir literatura y realidad al presentar el restaurante Casa Leopoldo como uno de "los locales preferidos de Pepe Carvalho, el héroe de las novelas de Manuel Vázquez Montalbán” (Furió sn).

Podría considerarse que resulta una ironía del destino que un autor y su personaje que tanto despreciaban a los turistas se hayan convertido en productos turísticos. Estas iniciativas se inscriben en lo que llamamos el turismo literario (en este caso particular es más bien gastro-literario) que se define generalmente como el hecho de visitar los lugares de nacimiento o de muerte de un escritor, pero también como el hecho de pasear por el "decorado" de una obra literaria. Como lo apuntan los universitarios Marta Magadán Díaz y Jesús Rivas García:

La obra literaria en este caso no ha sido ni pensada ni imaginada para fomentar la llegada de turistas o excursionistas al destino empleado como personaje de fondo. Por tanto, el libro actuaría como una vía indirecta de promoción favoreciendo, incluso, una mejor segmentación del mercado por el perfil de quien se acerca a la obra narrativa considerada en particular (Magadán Díaz, Rivas García 7).

El adjetivo literario le da otra dimensión al sustantivo "turismo". Ennoblece una práctica que tiende a considerarse como un incontestable recurso económico, pero también como una plaga, sobre todo últimamente con la problemática de los pisos de alquiler por temporadas y los estragos causados por celebraciones que se han convertido en una práctica basada en el exceso de todo tipo: las despedidas de solteros de las que se quejan los vecinos. En este panorama tan desolador, me parece que la propuesta de un turismo literario ofrece un buen compromiso para que los que no solo buscan canciones del verano, paella congelada, mojito de garrafón en la playa y amores fugaces, encuentren también cocteles de cava, buñuelos de bacalao y quizás algún que otro adolescente sensible y/o una muchacha dorada.

\section{Bibliografía}

Balibrea, Maripaz. "Viaje al fin del mundo: Política del tiempo y el espacio en Milenio Carvalho" en Colmeiro, José. Manuel Vázquez 
“HAacemos turismo o viajamos, Biscuter?” Manuel Vázquez...

Montalbán, El compromiso por la memoria, Woodbridge: Tamesis, 2007, 197-209.

Equipe MIT. Tourismes 1: Lieux communs. Paris: Belin, 2002.

Fuentes Vega, Alicia. Aportaciones al estudio visual del turismo: la iconografía del boom de España, 1950-1970, 2015. Tesis disponible en internet, http://eImpresos.ucm.es/32729/

Furió, María José. Cartoville Gallimard Barcelona. Barcelona: Ediciones B, 2016.

Gaudier, Céline. Entre touriste et voyageur: le troisième homme. Mémoire de licence de géographie, Université de Genève, 2002. Impreso

Gautier, Théophile. Viaje a España, Barcelona: Taifa, 1985.

Lévy, Bertand. "Voyage et tourisme. Malentendus et lieux communs", in Le Globe. Revue genevoise de géographie. Vol. 144, $\mathrm{n}^{\circ}$ 1, 2004, 123-136.

Littré, Émile. Dictionnaire de la langue française. Paris: L. Hachette, 1873-1874. Electronic version created by François Gannaz. http://www.littre.org. Obtenida el 17 de septiembre de 2018.

Magadán Díaz, Marta, Jesús Rivas García. Turismo literario, Oviedo: Septem ediciones, 2011.

Martínez Puche, Antonio. "El cine como soporte didáctico para explicar la evolución del viaje y la actividad turística" in Cuadernos de Turismo, Universidad de Murcia, no 22, 2008, 145-163.

McCannell, Dean. "Staged authenticity: Arrangements of Social Space in Tourist Settings". American Journal of Sociology, 79(3), 1973, 589-603.

Tyras, Georges. "Milenio Carvalho, una vuelta al mundo de la literatura", en José Manuel López de Abiada et alii, Manuel Vázquez Montalbán desde la memoria. Ensayos sobre su obra. Madrid, Editorial Verbum, 2010, p. 536-549.

Vázquez Montalbán, Manuel. "Turismo, Medio de incomunicación de masas", in Construcción, Arquitectura, Urbanismo (CAU), marzo de 1970.

---. Crónica sentimental de España, Barcelona: Lumen, 1970.

---. Los pájaros de Bangkok. Barcelona: Planeta, 1997.

---. Milenio Carvalho, Barcelona: Planeta: Booket, 2010. 